\title{
Interpretation of Korean null pronouns in subject and object position: Comparing native and non-native speakers
}

\author{
Silvia Kim \& Elsi Kaiser*
}

\begin{abstract}
We report an experiment that investigates how native and non-native Korean speakers' interpretation of null pronouns in subject and object position is influenced by structural and discourse-level factors. We compare native Korean speakers to L2 Korean learners whose L1, Spanish, only has null pronouns in subject position. We find that native Korean speakers' interpretation of subject and object null pronouns is guided by structural factors as well as discourse-level coherence relations, with subject nulls being more sensitive to coherence relations than object nulls. In contrast, our results suggest that L2 speakers' interpretation of null pronouns in Korean is less influenced by coherence relations. Our results support claims that interface phenomena are challenging in L2 acquisition and provide new evidence that this occurs with null pronouns in L2 even when the L1 has null pronouns.
\end{abstract}

Keywords. pronoun interpretation; null pronouns; coherence relations; Korean; Spanish; second language acquisition; Interface Hypothesis

1. Introduction. The need to refer to already mentioned entities in discourse is a very common and fundamental part of human communication and has been researched from many different perspectives. Languages often provide multiple linguistic options for speakers to refer to the intended referents (e.g., nouns, overt and null pronouns, demonstrative pronouns). With pronouns, comprehenders are faced with the task of identifying the intended antecedent. Here, we look at Korean to investigate how comprehenders - both native and non-native speakers - identify the intended antecedent when they are faced with an under-informative form like a null pronoun.

Following Givón (1983), Ariel (1990), Gundel et al. (1993), inter alia, there are several properties that guide reference resolution: (i) properties of the antecedent itself, (ii) the nature of the referential form, (iii) aspects of the linguistic context, and (iv) individuals' cognitive abilities such as differences in the working memory (see also Kaiser \& Fedele 2019 for an overview). Many researchers agree that multiple factors guide the process of reference resolution.

Very broadly speaking, prior work on pronoun interpretation largely falls into two general approaches. The first one is a mostly structurally based heuristics approach focusing on aspects like subjecthood and structural parallelism as guiding pronoun resolution. Factors such as being a topic, being a subject, being discourse-old and being in the same grammatical position as the pronoun (parallel function preference) have all been argued to play a role (Givón 1983, Ariel 1990, Crawley et al. 1990, Smyth 1994, Grosz et al. 1995, among many others). The second approach is a more discourse-based coherence relation approach, which views pronoun interpretation as a by-product of general reasoning about relations in discourse (e.g., Hobbs 1979, Kehler 2002, Kertz, Kehler \& Elman 2006, Rohde \& Kehler 2008, Ueno and Kehler 2010, 2016, Kaiser 2011, among others). Research has not yet converged on one over the other (but see Kehler \& Rohde 2013 for a reconciliatory approach).

\footnotetext{
${ }^{*}$ We thank the audience of the $95^{\text {th }}$ Annual Meeting of the Linguistics Society of America and the members of the Language Processing Lab at USC for useful comments and feedback. Thanks also to Danbi Ahn (UCSD) for sharing with us the Korean version of the Multilingual Naming Test (MiNT). Authors: Silvia Kim, University of Southern California (silbiaki@usc.edu) \& Elsi Kaiser, University of Southern California (emkaiser@usc.edu)
} 
We contribute to this discussion by investigating the interpretation of Korean null pronouns in subject and in object position, going beyond prior psycholinguistic work which has largely focused on subject-position null pronouns. Looking beyond subject-position null pronouns allows us to evaluate whether the grammatical position of a pronoun has any bearing on whether (or to what extent) its interpretation is guided by heuristic-based vs. coherence-based considerations. Furthermore, we compare native Korean speakers and L2 Korean learners whose L1, Spanish, only has null pronouns in subject position, to assess (i) whether these two groups are sensitive to coherence relations between clauses (in our study, signaled by the connectives 'and' and 'so'), and (ii) to see how L2 speakers interpret null pronouns in a position not available in their L1. This allows us to test claims that L2 learners struggle with interface phenomena such as reference resolution (Sorace \& Filiaci 2006: Interface Hypothesis).

This paper is organized as follows. In Section 2, we review prior work on pronoun interpretation. In Section 3, we introduce our research questions and predictions. Section 4 presents Experiment 1 (L1 Korean speakers), and Section 5 presents Experiment 2 (L1 Spanish speakers who are L2 learners of Korean). In Section 6, we discuss the results and future directions.

2. Languages differ in their pronominal options. There are considerable cross-linguistic differences in the nature of referential expressions. For example, English is not a pro-drop language, and only has overt pronouns (e.g., he, she, it, him, etc.), with the exception of very constrained contexts (see e.g., Haegeman 1990, 1997 on so-called 'diary drop'). Some other languages allow pronouns to be 'dropped' (i.e., to be phonologically null) much more freely. For example, Romance languages like Spanish and Italian allow null pronouns in subject position, and languages like Korean and Japanese allow both subject and object null pronouns. Romancetype languages are often called pro-drop languages, whereas Korean- and Japanese-type languages are often called discourse-oriented topic-drop languages (see also Huang 1984). The main reason why we chose to investigate Korean null pronouns is because unlike English or Spanish, it allows null pronouns in both subject and object position.

There is considerable prior psycholinguistic work on the interpretation of subject-position null pronouns. In an influential paper, Carminati (2002) proposed the Position of Antecedent Hypothesis, according to which null pronouns prefer antecedents in spec-IP position and overt pronouns prefer antecedents positioned lower in the syntactic tree. In addition to Carminati's work on Italian, there is also support for the Position of Antecedent Hypothesis in Spanish (Alonso-Ovalle et al. 2002). Consider the Spanish examples in (1):
a. María saludó a Ana. $\unrhd$ Está contenta. Maria greeted to Ana. $\emptyset$ is happy.
'Maria greeted Ana. $\underline{\emptyset}$ is happy.'
b. María saludó a Ana. Ella está contenta.
María greeted to Ana. She is happy.
'Maria greeted Ana. She is happy.'

Research by Alonso-Ovalle et al. (2002) found that overt pronouns (ex.1b) are interpreted as referring to the subject antecedent $50.2 \%$ of the time, whereas null pronouns (ex.1a) are interpreted as referring to the subject antecedent $73.2 \%$ of the time. Thus, in (1a) the null pronoun has a clear preference for the antecedent in subject position (María), whereas the overt pronoun in (1b) is more ambiguous between the preceding subject and object.

Now let us consider the following examples from Korean, from Kweon (2011): 


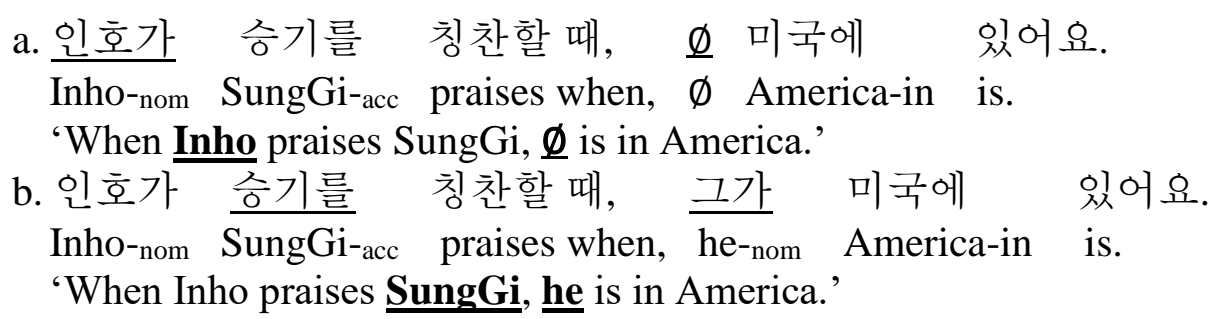

The Position of Antecedent Hypothesis predicts that Korean speakers would associate the null pronoun with the antecedent in spec-IP position (the subject) and the overt pronoun with the object. (In this paper, we use the term 'null pronoun' in a broad sense, and we also use it for languages like Korean that are commonly viewed as being topic-drop languages.) Indeed, according to Kweon (2011), when given examples like (2a) with a null pronoun, most participants preferred the subject interpretation (Inho), whereas for the overt pronoun in (2b), people preferred the object interpretation (SungGi).

These prior studies provide crosslinguistic evidence for the Position of Antecedent Hypothesis for subject-position null pronouns. However, these results do not speak directly to the interpretation of null pronouns in object position. In a different line of research, investigators have looked at the effects of grammatical function parallelism on the interpretation of overt pronouns in object position. In an influential paper, Smyth (1994) concludes that "A pronoun with two or more grammatically and pragmatically possible antecedents in a preceding clause will be interpreted as coreferential with the candidate that has the same grammatical role." Thus, grammatical role parallelism effects push subject position pronouns to be interpreted as referring to the preceding subject and object position pronouns to be interpreted as referring to the preceding object (see e.g., Sheldon 1974, Smyth 1994, Chambers \& Smyth 1998). However, prior work on parallelism has largely focused on overt pronouns, but see e.g., Ngo (2019) and Song \& Kaiser (2020) on parallelism effects with null pronouns in object position in Vietnamese and Korean.

It is important to acknowledge that it is not only the syntactic position of the pronouns and their antecedents that matters when interpreting pronouns. A growing body of work shows that pronoun resolution is influenced by the semantic coherence relations between clauses (e.g., Hobbs 1979, Kehler 2002, Kehler et al. 2008). Indeed, according to Hobbs, pronoun interpretation is best viewed as a by-product of general reasoning about discourse coherence. Consider the examples in (3), partially adapted from Smyth (1994).
a. Phil tickled Stanley, and Liz poked him. [coherence relation: parallel]
b. Phil tickled Stanley, so Liz poked him. [coherence relation: result]
c. Phil tickled Stanley, and he poked Liz.
[coherence relation: parallel]
d. Phil tickled Stanley, so he laughed.
[coherence relation: result]

These kinds of examples show that overt pronoun interpretation is sensitive to coherence relations. As shown empirically by Smyth (1994), Chambers \& Smyth (1998), Wolf et al. (2004), Kertz et al. (2006) inter alia, overt object position pronouns in English show a preference for the grammatically (and semantically) parallel antecedent (preceding object) in configurations like (3a). (It's worth noting that the connective 'and' is ambiguous and compatible with multiple coherence relations, including parallel as well as a narrative/occasion/'what happened next' relation. We return to this point below.)

However, as noted by Kehler (2002) and Kertz et al., (2006), this parallelism preference no longer holds when the coherence relation between the clauses is result (as signaled by the connective 'so'), as in example (3b). Similar results obtain for subject position pronouns in English, 
as illustrated in (3c) vs. (3d): Whereas subject position pronouns tend to favor subject antecedents when the two clauses are linked by a parallel relation, this preference is weakened in the presence of a result relation (e.g., Kertz et al., 2006). In sum, prior work shows that the coherence relations between clauses can bias the interpretation of pronouns, suggesting that an account focusing only on grammatical roles of the pronoun or the antecedent is unlikely to be sufficient.

These observations about coherence effects on overt pronouns in both subject and object position raise the question of what happens with null pronouns. Does their interpretation also show sensitivity to coherence relations? Earlier work on Japanese (Ueno \& Kehler, 2010) and on Korean (Kim et al. 2013) provides initial evidence for coherence effects.

In a recent study on Korean, Song \& Kaiser (2020) found effects of explanation vs. parallel relation on null pronoun interpretation in Korean. There are also studies looking at how speakers of null-subject languages use overt pronouns in the L2 and how speakers of overt-pronoun languages use null subjects in the L2 (e.g., Gürel 2003, 2004, Sorace \& Filiaci 2006, Roberts et al. 2008, Sorace \& Serratrice 2009). However, to the best of our knowledge, prior work has not systematically compared effects of coherence relations (result/parallel relation) on the interpretation of null pronouns in both subject and object position in a study that looks at both native and L2 speakers whose native language only has null pronouns in subject position.

3. Research questions and predictions. Our goals are to investigate (i) how native Korean speakers interpret null pronouns in subject and object position and to investigate (ii) how L2 speakers of Korean (with Spanish as L1) differ from Korean monolinguals in the interpretation of null pronouns. Our research questions are: Do coherence relations (result vs. parallel) influence interpretation of Korean null pronouns in subject and object position by L1 Korean speakers (Exp 1) and L1 Spanish L2 Korean speakers (Exp 2). Relatedly, how do L2 speakers interpret null pronouns in a position not available in their L1?

We use two connectives: (i) kulayse ('so') which signals a result relation and (ii) kuliko ('and'), which is compatible with a parallel relation. Although the connective kuliko ('and') is somewhat ambiguous in Korean in allowing for multiple coherence relation construals (similar to English and many other languages), we refer to 'and' as a parallelism-indicating connective in the rest of this paper. Its default reading is influenced heavily by the grammatical role of the pronoun and we want to make clear that it contrasts with the result-indicating connective 'so' (see e.g., Kaiser 2011 on German). What is most relevant for us is that kulayse ('so') unambiguously indicates a result relation, whereas kuliko ('and') does not.

We also aim to test claims that L2 learners struggle with interface phenomena (interface hypothesis, Sorace \& Filiaci 2006). Can learners attain native-like performance with null object pronouns in the L2? Spanish and Korean are ideal for investigating this.

In the present study, we address these questions by means of a picture-writing task where participants see a sentence accompanied by picture with stick figures depicting the characters mention in the sentence (see Figure 1). The participants' task is to type the names of the characters below the corresponding stick figures. As explained in Section 4.3, this allows us to infer how participants interpret null pronouns.

The research questions outlined above can provide novel evidence of how Korean monolinguals' interpretation of null pronouns is influenced by coherence relations, as well as how L2 speakers of Korean whose first language is Spanish - which only has null pronouns in subject position - interpret null pronouns in Korean in both subject and object position. For the subject null pronouns, one might expect the L2 speakers to use their native Spanish strategy, i.e., to show transfer effects. However, since their L1 has no null pronouns in object position, the 
Korean null pronouns allow us to test how participants tackle reference resolution of a null form in a configuration absent in their L1. This allows us to explore whether learners struggle with grammar external factors, as suggested by the Interface Hypothesis proposed by Sorace \& Filiaci (2006). Alternatively, if L2 learners are influenced by their L1 (Spanish) even when dealing with null pronouns in a configuration absent in the L1, we might expect participants to adapt the Spanish subject null pronoun interpretation strategy to resolve the Korean object nulls as well.

\section{Experiment 1: Korean monolinguals}

4.1. PARTICIPANTS. Fifty-one native speakers of Korean participated in the experiment. They were all born and raised in Korea and were self-identified native speakers of Korean. None had experience living outside of Korea and according to the background questionnaire, none had acquired fluency in a second language. Four participants were excluded because their accuracy for the unambiguous textbox on target sentences (as explained below) was below $80 \%$. This left 47 participants for the final analysis. All participants had normal or corrected-to-normal vision and hearing and did not report any reading or learning disabilities.

4.2. MATERIALS AND DESIGN. The experiment used a $2 \times 2$ design (connective type $\mathrm{x}$ grammatical position of the null pronoun). Targets consisted of two sentences, as shown in example (4). The sentences were separated by a period, followed by a connective. Although it is not standard to start a sentence with a connective in English, in Korean this is normal (see e.g., Sohn 2019).

아영이가 지아를 의건했다. 그리고 $\emptyset$ 사라를 도와주었다. [subject null pro] Ahyoung-nom Jiah-acc zorked. And $\emptyset$ Sarah-acc helped.

'Ahyoung zorked Jiah. And $\emptyset$ helped Sarah.'

In target items, the first sentence is a transitive SOV sentence with two animate arguments, realized with proper names. The names are marked with the nominative marker (subject) or the accusative marker (object) and followed by a nonce verb. ${ }^{1}$ We used nonce verbs in the first sentence to eliminate verb semantics and gain an understanding of how the 'default' resolution for null pronouns happens when only information from the connective and grammatical position of the null pronoun is available. Therefore, using nonce verbs in the first sentence allows us to zero in on the question of whether the coherence relation and the pronoun's grammatical role influence reference resolution. The nonce verbs are pronounceable in Korean; they were combined with the Korean dummy verb - $h a$ ' do'. This made it clear that all verbs were in the active voice. ${ }^{2}$

In the second sentence, we manipulated whether the null pronoun is in subject or object position. The location of the null pronoun was indicated by the presence of a nominative or accusative marker on the overt argument. When the name in the second sentence was marked with a nominative marker, this indicated that the null pronoun was in object position and vice versa. In addition to manipulating the position of the null pronoun, we also manipulated the nature of the connective linking the two sentences: it was either the result-indicating connective kulayse ('so') or the parallelism-indicating connective kuliko ('and').

The verbs used in the second sentence were real transitive agent-patient verbs (e.g., 'found', 'helped', 'congratulated', 'trusted'). The arrows and stick figures depicted in the picture accompanying each item also made it clear that the verb in the second sentence is transitive (see Figure 1). An example of a full target item is in Table 1 . In Table 1, the symbol $\emptyset$ stands for the null

\footnotetext{
${ }^{1}$ We used same-gender names in each item and a mix of Korean and Spanish names.

${ }^{2}$ The majority of the nonce verbs used were taken from Song \& Kaiser (2020).
} 
pronoun. We use it here for expository clarity. This symbol was not shown to participants.

\begin{tabular}{|c|c|c|}
\hline \multirow{2}{*}{$\begin{array}{l}\text { Null pronoun: } \\
\text { Subject }\end{array}$} & And & $\begin{array}{l}\text { 아영이가 지아를 의건했다. 그리고 } \emptyset \text { 사라를 도와주었다. } \\
\text { Ahyoung-nom Jiah-acc zorked. And } \emptyset \text { Sarah-acc helped. } \\
\text { "Ahyoung zorked Jiah. And } \emptyset \text { helped Sarah.' }\end{array}$ \\
\hline & So & $\begin{array}{l}\text { 아영이가 지아를 의건했다. 그래서 } \emptyset \text { 사라를 } \quad \text { 도와주었다. } \\
\text { Ahyoung-nom Jiah-acc zorked. So } \emptyset \text { Sarah-acc helped. } \\
\text { 'Ahyoung zorked Jiah. So } \emptyset \text { helped Sarah.' }\end{array}$ \\
\hline \multirow{2}{*}{$\begin{array}{l}\text { Null pronoun: } \\
\text { Object }\end{array}$} & And & $\begin{array}{l}\text { 아영이가 지아를 의건했다. 그리고 사라가 } \emptyset \text { 도와주었다. } \\
\text { Ahyoung-nom Jiah-acc zorked. And Sarah-nom } \emptyset \text { helped. } \\
\text { "Ahyoung zorked Jiah. And Sarah helped } \emptyset .\end{array}$ \\
\hline & So & $\begin{array}{l}\text { 아영이가 지아를 의건했다. 그래서 사라가 } \emptyset \text { 도와주었다. } \\
\text { Ahyoung-nom Jiah-acc zorked. So Sorah-nom } \emptyset \text { helped. } \\
\text { 'Ahyoung zorked Jiah. So Sarah helped } \emptyset .\end{array}$ \\
\hline
\end{tabular}

Table 1. A set of example stimuli

In addition to the 24 targets, the study included 4 practice items and 36 fillers. Fillers had a mix of sentence types (e.g., transitives, ditransitives, relative clauses) and some contained nonce nouns and verbs. Some fillers served as comprehension questions/attention checks. Target and filler items were pseudo-randomized into four lists using a Latin-Square design. Each person saw each target item once; each of the four conditions appeared the same number of times per list.

4.3. PROCEDURE. Participants were shown a picture depicting the event described in the second sentence and they were asked to write the names of the characters into the text boxes below the corresponding stick figure (Figure 1). We used a web-based interface to present the stimuli and to collect data (Qualtrics, Provo, UT, https://www.qualtrics.com/).

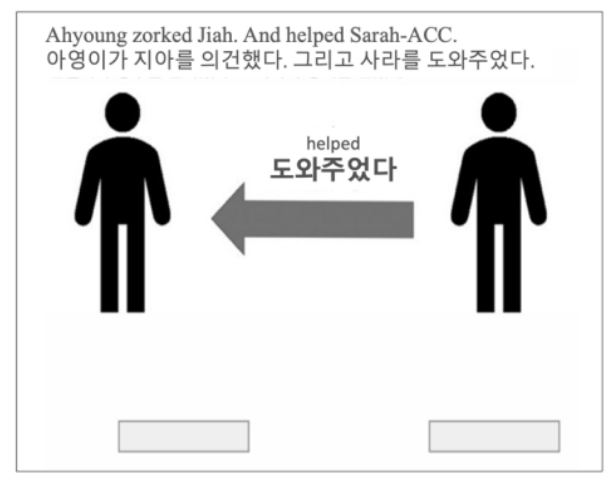

Figure 1. Sample item illustrating a sentence with a null pronoun in subject position (The English text was not shown to participants)

The gender of names, the directionality of arrows, and the left/right location of the stick figure that corresponds to the null pronoun position were counterbalanced. Participants were instructed to type the name of each person in the textbox below the stick figure depicting that person. In the example in Figure 1, the null pronoun is in subject position, as indicated by the accusative case- 
marking on the overt argument in the second sentence, Sarah. Therefore, the left textbox (under the object character) is unambiguous - the only possible answer for that box is Sarah. We call this the 'unambiguous name' textbox. Participants' responses to this box allow us to check if they correctly recognized the location of the null pronoun by using the cue from the case markers. As will become clear below, this is especially important in the case of the L2 learners to ensure that they are correctly understanding the structure of the second sentence and realizing where the null pronoun is. It also serves as an additional attention check with native speakers.

Crucially, only the box corresponding to the character referred to with the null pronoun is ambiguous. In Figure 1, this is the right box. This provides the crucial data for our main analysis, as it allows us to assess how people interpret the null pronoun. We call this the 'ambiguous name' textbox. In Figure 1, participants could type 'Ahyoung' into the right box (in which case we would infer that they think the null refers to the preceding subject) or they could type 'Jiah' into this box (and then we would infer that they think the null refers to the preceding object).

4.4. PREDICTIONS. For L1 speakers, we predict that with kuliko ('and'), responses in the ambiguous name textbox will reveal a preference for the null to refer to the character in the parallel grammatical position: If the null pronoun is in subject position, it will refer to the preceding subject and if the null pronoun is in object position, it will refer to the preceding object. With the connective kulayse ('so'), which indicates a result relation, we expect a weaker preference for the parallel antecedent, or perhaps a preference for the non-parallel antecedent.

4.5. RESULTS. Participants had to get above $90 \%$ accuracy on catch trials and above $80 \%$ accuracy in the unambiguous textbox responses on target sentences to be included in the analysis. Thus, we excluded 4 participants and the remaining 47 were included in the final analysis. The results are shown in Figure 2. The $\mathrm{x}$ axis shows how often the null pronoun refers to the entity in the same grammatical position. In other words, the y axis shows how often a null pronoun in subject position is interpreted as referring to the preceding subject, and how often a null pronoun in object position is interpreted as referring to the preceding object.

\section{L1 Null pro referring to the antecedent in parallel position}

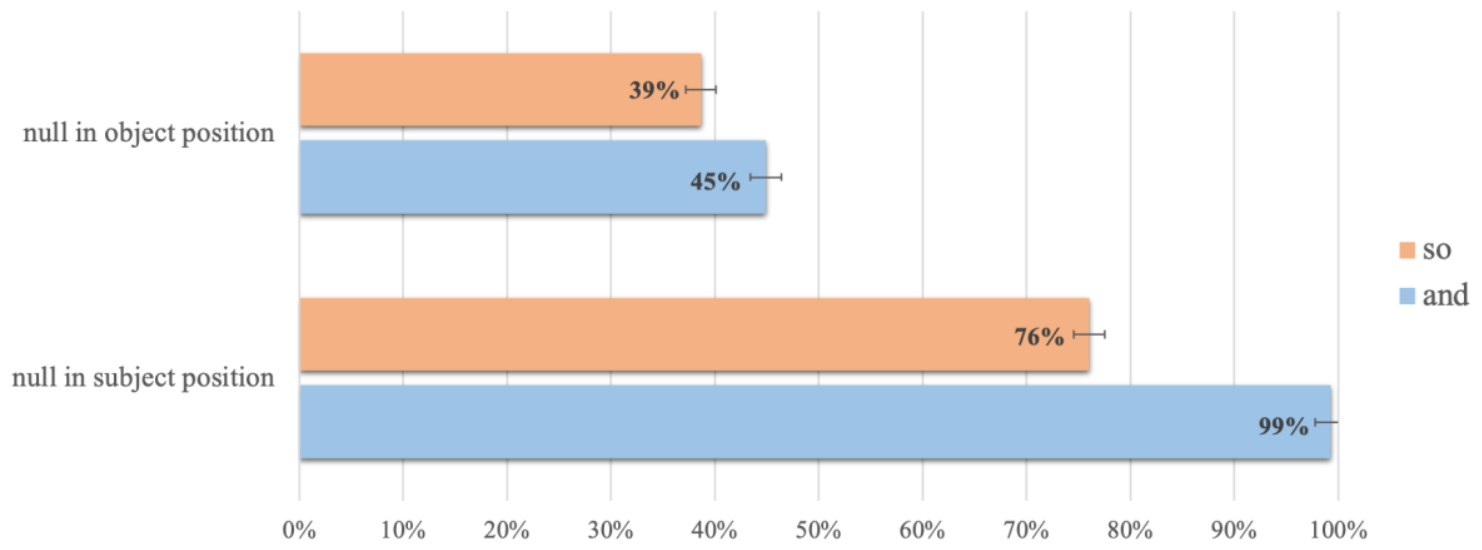

Figure 2. Native Korean speakers (Exp 1)

We fit a generalized linear mixed logit model to assess effects of connective and grammatical role of the pronoun using the lme4 package (Bates et al., 2015) in R (R Core Team, 2020). For both independent variables, we coded +0.5 corresponding to connective 'and', and -0.5 to the connective 'so', as well as +0.5 to 'subject position null' and -0.5 for 'object position null'. The dependent variable was defined in terms of whether the null pronoun is interpreted as referring to 
the preceding parallel referent $(1=$ parallel, $0=$ not parallel). Thus, 1 means that the null pronoun refers to the entity in the parallel structural position, i.e., the preceding subject for subject-position null pronouns, the preceding object for object position null pronouns. (We chose to not analyze the proportion of subject choices across the board, as that would not allow us straightforwardly to compare the strength of the parallelism effect for subject and object position nulls.)

As one might expect based on Figure 2, the statistical analyses reveal a main effect of connective ( $\mathrm{p}<0.001$ ): the connective kuliko ('and,' parallel; blue bars) pushes people to interpret pronoun as referring to the parallel referent more than kulayse ('so,' result; reddish bars).

We also find a main effect of null pronoun position $(\mathrm{p}<0.001)$ : subject position nulls prefer subject referents more strongly than object nulls prefer object referents. This finding that subject nulls exhibit a stronger parallelism effect than object nulls is unexpected given prior work on English parallelism effects. Based on prior work on parallelism effects exhibited by overt pronouns in English, we would have expected nulls in object position to show a strong preference for object antecedents. Instead, it seems like subjecthood may be playing a role with object position nulls as well. This finding fit with the general finding that subjects are salient and good antecedents for pronouns. However, since the difference in the strength of the parallelism effect between subject and object position nulls is not the central focus of the current work, we leave more detailed investigation of this issue as a topic for future work.

Finally, there is also a connective type $x$ grammatical role interaction $(p<0.001)$ : subject nulls are more sensitive to the connective manipulation (and vs. so) than object nulls. This is reflected in the blue bar-red bar difference being bigger for subject position nulls than for object position nulls). Nevertheless, planned comparisons confirm that both subject nulls and object nulls are sensitive to the coherence manipulation ( $p$ 's $<0.05$ ): the result-indicating kulayse ('so') connective makes people less likely to interpret the null as referring to the parallel referent than kuliko ('and'), regardless of whether the null pronoun is in subject or object position.

4.6. DISCUSSION. In Experiment 1, we looked at native Korean speakers' interpretation of null pronouns in (i) subject vs. object position and (ii) in contexts involving parallel coherence relations vs. result coherence relations. Our experiment shows that coherence information from connectives guides interpretation of null pronouns in both subject and object position. When two sentences are linked with the result-indicating connective kulayse ('so'), participants are less likely to interpret a null pronoun as referring to the antecedent in the parallel grammatical position than when the sentences are connected with kuliko ('and'). The effect of connective type is weaker for object null pronouns than subject null pronouns, but it is still significant. This shows that in the absence of cues from verb semantics (recall that we used a nonce verb in the first sentence), people made use of information from the connectives to interpret the null pronoun.

In sum, Experiment 1 provides novel evidence that while Korean subject and object null pronouns are sensitive to structural factors and to coherence relations, subject null pronouns show more sensitivity to coherence. Broadly, our results support the coherence relation approach (Hobbs 1979, Kehler 2002, Rohde \& Kehler 2008, Kaiser 2011, Ueno \& Kehler 2016, inter alia).

We will now move on to the second experiment with L2 learners of Korean. Experiment 2 tests how L1 Spanish speakers learning Korean as a second language interpret Korean null pronouns. We mainly look at if they show similar patterns as the monolinguals in Experiment 1.

\section{Experiment 2: Native Spanish speakers learning Korean}

\subsection{PARTICIPANTS. Thirty-eight L2 speakers of Korean participated in exchange for pay (\$10).}


They were all born and raised in Costa Rica, and self-identified as native speakers of Spanish. Three participants were excluded because they did not finish the study, and three more because their accuracy for filling in the 'unambiguous name' textbox in targets was below $40 \%$. (Recall that, as discussed in Section 4.3, this allows us to check whether participants can recognize the grammatical position of the null pronoun based on the case-marker on the overt name.) This left 32 participants for the final analysis. All participants had normal or corrected-to-normal vision and hearing and did not report any reading or learning disabilities.

A detailed language background questionnaire was conducted for every participant. Questions were about their languages (languages they speak, self-rated proficiency for all sections of language competence (speaking, listening, reading, and writing), age when they first acquired each language and how it was learned, exposure and use of each language in a daily life basis, etc.), country of birth and countries they have lived in, language use with family and friends, and language use depending on different situations, etc.) The experiment was conducted by the first author in Costa Rica. Students who had or were currently attending Korean classes (at Universidad Nacional de Costa Rica, Universidad de Costa Rica, Tecnológico de Costa Rica, Instituto Nacional de Aprendizaje) were recruited. The majority of the students had completed two semesters of Korean classes (beginner level 1 and 2). Some were in intermediate level classes.

5.2. MATERIALS AND DESIGN. The materials and design were the same as in Experiment 1 . We made sure that all participants were familiar with the Korean case markers and the transitive verbs used in the experiment by checking the textbooks used in their Korean classes and through discussions with their Korean professors. (Whether L2 speakers can recognize nonce words as such is not problematic: Regardless of whether they recognize a nonce verb as being made-up or assume it's a real verb that they just don't know, the consequence is the same: Participants cannot use information from verb semantics, which is exactly the intended effect.)

5.3. PROCEDURE. The procedure was as in Experiment 1. The instructions were written in Korean, but the experimenter also explained the instructions verbally in Spanish. For Experiment 2, we added two more tasks: (i) the Korean version of the Multilingual Naming Test (MiNT), originally developed Gollan et al. (2012) and adapted to Korean by Danbi Ahn at the Language Production Lab at UC San Diego, and (ii) a language background questionnaire. In the MiNT task, participants saw drawings of 30 words (varying from low to high frequency, and low to high level in difficulty), and their ability to accurately name the pictures in Korean was assessed.

The sequence of the experiment was as follows: The experimenter first asked a few questions about the participant's language background and explained the instructions, and the participant did some practice questions with the experimenter. Then the participant completed the experiment on a laptop using Qualtrics. Afterwards, the participant did the MiNT task and was asked the remaining follow-up questions from the language background questionnaire. The whole process took around 50 minutes to complete.

5.4. PREDICTIONS. Recall that Spanish has null pronouns in subject but not object position. We are most interested in participants' interpretation of object nulls since this configuration is not available in their L1, as well as their sensitivity to the coherence manipulation (and/so).

According to the Interface Hypothesis (Sorace \& Filiaci 2006, Sorace 2011), L2 learners are able to acquire syntactic properties but struggle with grammar external domains (e.g., interface between syntax and other cognitive domains). For this reason, one might expect second language learners to experience difficulties with (certain aspects of) reference resolution, given that this process involves the interface between syntax and discourse/pragmatics. If L2 learners are not 
very sensitive to coherence relations - which are presumably grammar-external factors - the Interface Hypothesis leads us to expect that we might observe less sensitivity or no significant difference between the connectives 'and' and 'so'.

Moreover, we might see an overall stronger preference for subject position referents. Since Spanish only has null pronouns in subject position and prior Spanish work shows subject nulls prefer subject antecedents, L1 Spanish/L2 Korean speakers might overgeneralize this strategy and choose subject antecedents for both null pronouns in Korean.

5.5. RESULTS. We first present the results for all L2 speakers $(n=32)$, and then we consider them separately by proficiency level. In the rest of this section, to ensure that the comparisons between the subject- and object-position pronouns are meaningful, we only include data from those trials where L2 speakers correctly identified the location of null pronoun. (Recall that this is indicated by the nominative or accusative case marker on the overt noun in the second sentence and could be directly measured by what name participants indicated should go in the 'unambiguous name' text box). Figure 3 below shows the results for all L2 speakers. As in Figure 2 above, the $x$ axis shows how often the null pronoun refers to the entity in the same grammatical position.

\section{L2 Null pro referring to the antecedent in parallel position}

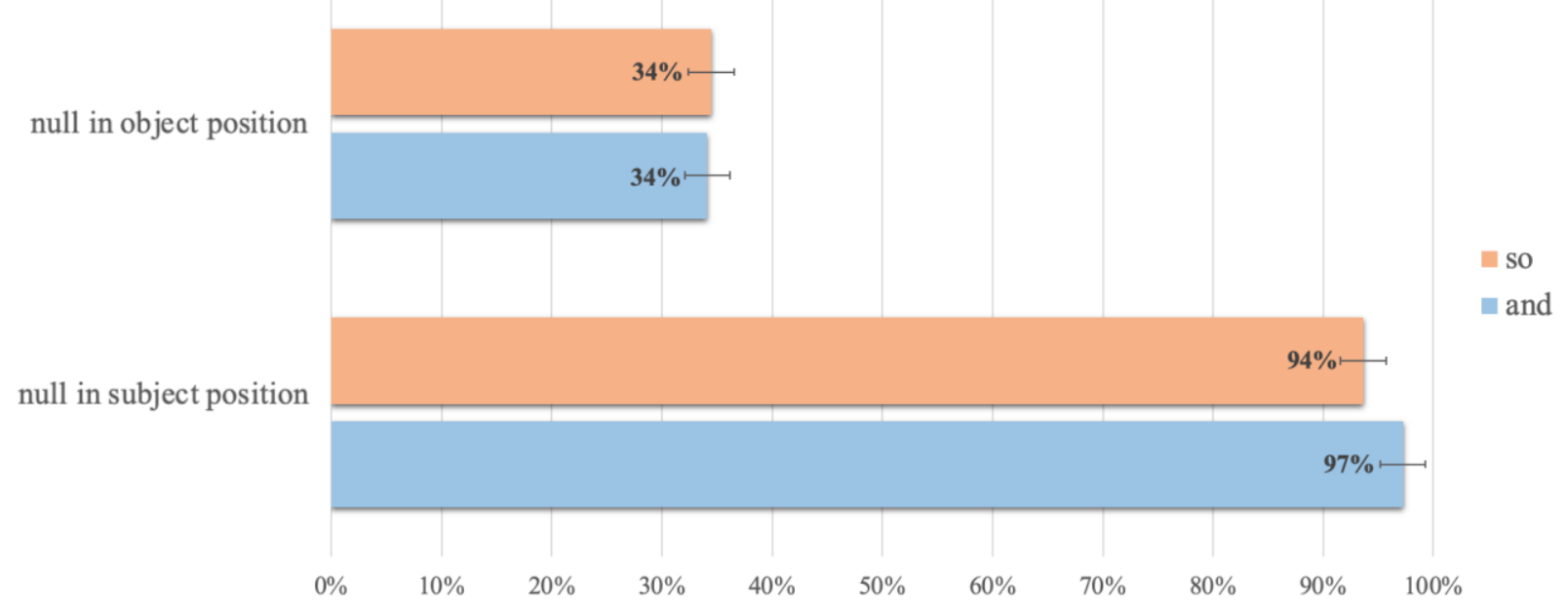

Figure 3. L2 Korean speakers (L1 Spanish) (Exp 2)

Our statistical analyses show no main effect of connective, and no connective x position interaction - in contrast to the data with L1 Korean speakers. With the entire group of L2 speakers, we only find a main effect of null pronoun position (glmer, $\mathrm{p}<0.001$ ): subject position nulls prefer subject referents more strongly than object nulls prefer object referents - something that we also found with the L1 speakers. To our knowledge, prior work on Spanish has looked at parallelism effects only with null pronouns and overt pronouns in subject position (Alonso-Ovalle et al., 2002). For future work, it will be interesting to look at object position pronouns as well. In sum, connectives did not impact L2 speaking participants' interpretation of null pronouns in Korean: We see no clear differences between the blue bars and the red bars.

5.6. PROFICIENCY. Let us now consider whether proficiency in Korean impacts resolution of null pronouns. Here, we define proficiency based on how accurately participants identified the position of the null pronoun. As discussed in Section 4.3 above, our task assessed both (i) null pronoun interpretation (by means of participants' answers in the 'ambiguous name' box) and (ii) 
participants' ability to understand the case markers and to infer the location of the null pronoun (by means of their answers in the 'unambiguous name' box). We were able to use this second type of information to identify for each participant their individual accuracy score for the 'unambiguous name' text box - in other words, how well that participant understands case markers. Using this score, we divided L2 speakers into two groups: a lower proficiency group (accuracy between 40-59\%), n=21 and a higher proficiency group (accuracy above $60 \%$ ), n=11.

We did not use the scores from the MiNT task as proficiency categorizer because this task turned out to not allow for good detectability of difference proficiency levels in our participant population: The MiNT probes vocabulary knowledge, and our participants - presumably due to similar textbooks/instruction - showed very similar (almost identical) vocabulary skills. Another possible means of categorizing participants' proficiency is based on their self-assessed proficiency, as reported in the language background questionnaire. However, this information could not be used because people's self-assessments tended to skew high and did not line up with other indicators of proficiency. Thus, we opted to use participants' performance on the 'unambigous name' box task, which measures their ability to use information from nominative and accusative case markers to identify the grammatical roles of the arguments in each sentence.

Before looking at the data by proficiency level, it's worth pointing out that the data in Figure 3 only included trials on which participants entered the correct name into the 'unambiguous name' textbox. Thus, we only looked at those specific trials where participants recognized the pronoun's grammatical position (subject or object). In that analysis, no participants were fully excluded (beyond the exclusions reported in Section 5.1); only individual trials were excluded.

Now, in this section, we are still excluding trials where participants answered the unambiguous textbox incorrectly, but in addition we are stratifying participants based on their average accuracy (across the entire experiment) on the 'unambiguous name' textbox responses. Thus, the data below is the same data as in Figure 3, but now broken down in terms of participants' ability to detect/use information from the case markers. The results from the higher proficiency group of L1 Spanish speakers learning Korean (Figure 4) are shown in Figure 4.

As one might expect from the figure, we again find a main effect of grammatical role $(\mathrm{p}<0.001)$ : subject position nulls prefer subject antecedents more than object position nulls prefer object antecedents. There is also a main effect of connective $(\mathrm{p}<0.05)$ : presence of 'and' pushes participants to interpret both subject nulls and objects nulls as being more likely to refer to an antecedent in the parallel grammatical position than presence of 'so'. These findings echo what we found with native speakers, though numerically the effect of the connective manipulation (differences between the blue and red bars) is smaller. Furthermore, unlike what we saw with Korean native speakers, there is no connective x position interaction.

The main effect of connective type suggests that high proficiency L2 learners are capable of using coherence relations to guide interpretation of null pronouns in both subject and object position. What about the low proficiency L2 group, whose data is shown in Figure 5?

Numerically, Figure 5 again shows an effect of grammatical position: subject nulls prefer the subject more strongly than object nulls prefer the object. Furthermore, in contrast to L1 speakers and higher proficiency L2 speakers, this group of lower proficiency L2 speakers shows effects of the connective manipulation in an unexpected direction: Numerically, 'so' elicits more parallel-antecedent choices than 'and' (the red bars are longer than the blue bars.) This is contrary to what research on coherence relations leads us to expect. Thus, as a whole, the low proficiency L2 speakers do not pattern in a native-like way when it comes to sensitivity to coherence relations. (Due to varying levels of accuracy on case marker recognition in the low 
proficiency group, statistical analyses have not been conducted. In future work with larger numbers of participants, we hope to conduct more detailed analyses to assess effects of proficiency.)

\section{L2 Null pro referring to parallel (Higher proficiency)}

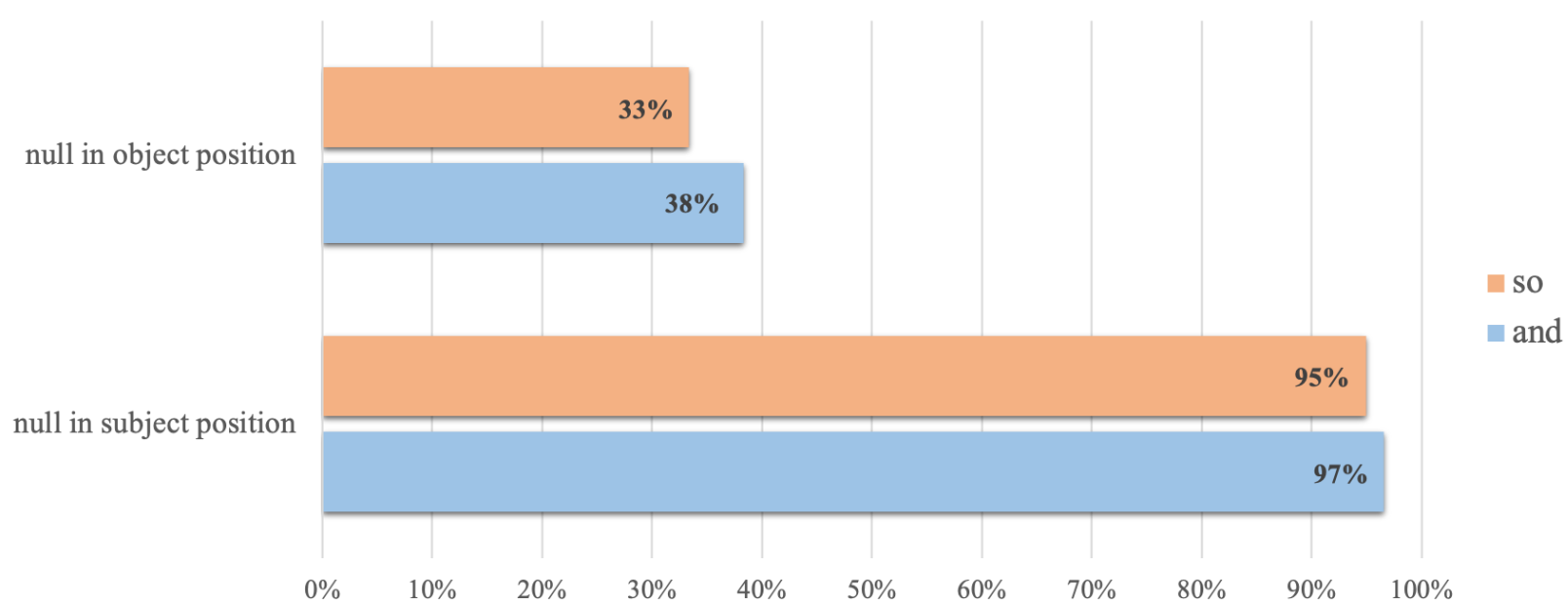

Figure 4. High proficiency L2 group (11 participants)

\section{L2 Null pro referring to parallel (Lower proficiency)}

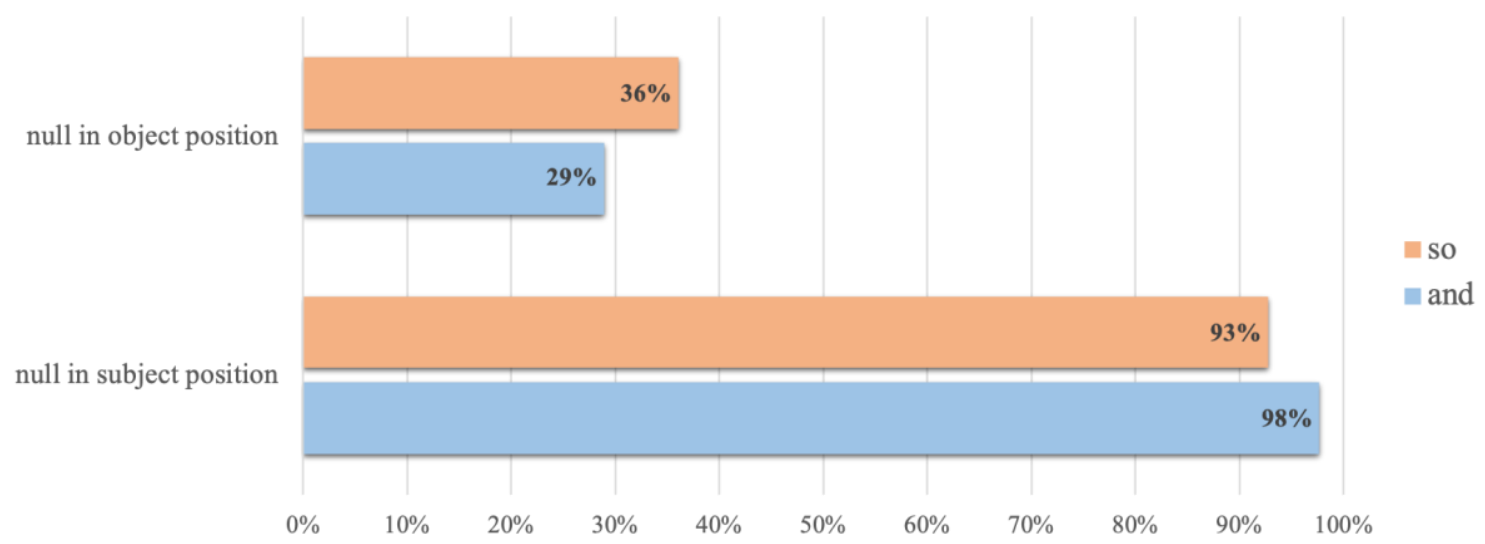

Figure 5. Low proficiency L2 group (21 participants)

5.7. DISCUSSION. When all L2 participants were analyzed together, native Spanish speakers who are studying Korean as an L2 did exhibit sensitivity to coherence relations. For subject position null pronouns, the subject antecedent was highly preferred regardless of connective type. Object pronouns similarly failed to show sensitivity to the connective manipulation. This is in line with predictions that can be derived from the Interface Hypothesis (Sorace \& Filiaci 2006).

Interestingly, echoing what we saw with native speakers, the preference for an antecedent in the parallel syntactic position is stronger with subject pronouns than with object pronouns. Even more than with native speakers, we find that (i) subject null pronouns prefer subject antecedents and (ii) object null pronouns also prefer subject antecedents. This pattern is unexpected given work on English parallelism effects, but fits with the general finding that subjects are salient and good antecedents for pronouns. Intriguingly, when looking only at the high proficiency group, we see evidence that higher proficiency L2 learners are sensitive to the coherence information provided by the connectives: Although their performance is not quite native-like, the coherence 
effects are in the expected direction. However, our participants numbers are small, so further examination is needed by testing more L 2 participants.

6. General discussion and conclusions. This paper reports two studies investigating the nature of Korean null pronoun interpretation by native Korean speakers and L2 learners of Korean whose first language is Spanish. Results for native Korean speakers (Experiment 1) suggest that null pronouns in both subject and object position are sensitive to information about coherence relations encoded on the connective (and/so), such that the parallelism-indicating connective $k u l$ $i k o$ 'and' boosts the likelihood of a null being interpreted as coreferential with an antecedent in the parallel syntactic position, when compared to the connective kulayse 'so'. Our results also indicate that subject nulls are more sensitive to the coherence manipulation than object nulls.

Experiment 2 tested L2 learners of Korean whose first language is Spanish. Spanish offers an interesting counterpart to Korean, since whereas Korean allows null pronouns in both subject and object position, Spanish only has nulls in subject position. Our results indicate that as a group, the L2 learners did not show sensitivity to the coherence manipulation. However, when we focused only on relatively higher-proficiency L2 speakers, we did find evidence in favor of coherence effects: Higher-proficiency L2 speakers are more likely to interpret a null pronoun as referring to an antecedent in the parallel grammatical position in the presence of the parallelismindicating connective 'and' as compared to 'so' which indicates a causal/result relation.

Thus, our results suggest that L2 learners are capable of using the cues from the connectives to interpret null pronouns at higher levels of proficiency. Our results provide only partial support for the Interface Hypothesis: lower-proficiency learners seem to struggle, but higher-proficiency learners show a similar pattern to the native Korean speakers. Thus, our study suggests nativelive performance on interface phenomena (involving grammar external factors) may be attainable, contrary to what one might expect based on the Interface Hypothesis.

However, many questions remain open. Larger numbers of L2 speakers of Korean of varying proficiencies should be investigated to further assess the validity of our results and conclusions. Moreover, it will also be crucial to test native Spanish speakers' interpretations of null subject pronouns and, given that Spanish object pronouns are not free-standing like English object pronouns, testing clitic object pronouns in different coherence configurations in Spanish will also be informative. This will (a) yield more information about Spanish and (b) provide an important foundation for interpreting our L2 data. This is necessary in order to better understand the role of L1 influence when interpreting pronouns in the L2. We also plan to extend our investigation to different bilingual populations such as L1 English/L2 Korean, L1 Japanese/L2 Korean as well as heritage speakers of Korean, to get a more inclusive picture of pronoun resolution.

\section{References}

Alonso-Ovalle, Luis, Susana Fernández-Solera, Lyn Frazier \& Charles Clifton. 2002. Null vs. overt pronouns and the topic-focus articulation in Spanish. Italian Journal of Linguistics 14. 151-170.

Ariel, Mira. 1990. Accessing noun-phrase antecedents. London: Routledge.

Bates, Douglas, Martin Mächler, Ben Bolker \& Steve Walker. 2015. Fitting linear mixed-effects models using lme4. Journal of Statistical Software 67(1).1-48. https://doi.org/10.18637/jss.v067.i0.

Carminati, Maria N. 2002. The processing of Italian subject pronouns. Amherst, MA: University of Massachusetts dissertation. 
Chambers, Craig G. \& Ron Smyth. 1998. Structural parallelism and discourse coherence: a test of centering theory. Journal of Memory and Language 39. 593-608. https://doi.org/10.1006/jmla.1998.2575.

Crawley, Rosalind A., Rosemary J. Stevenson \& David Kleinman. 1990. The use of heuristic strategies in the interpretation of pronouns. Journal of Psycholinguistic Research 19. 245264. https://doi.org/10.1007/bf01077259.

Givón, Talmy. 1983. Topic continuity in discourse: A quantitative cross-language study. Philadelphia/Amsterdam: John Benjamins.

Gollan, Tamar H., Gali Weissberger, Elin Runnqvist, Rosa I. Montoya \& Cynthia M. Cera. 2012. Self-ratings of spoken language dominance: A multi-lingual naming test (MINT) and preliminary norms for young and aging Spanish-English bilinguals. Bilingualism: Language and Cognition 15. 594-615. https:/doi.org/10.1017/S1366728911000332.

Grosz, Barbara J., Scott Weinstein \& Aravind K. Joshi. 1995. Centering: A framework for modeling the local coherence of discourse. Computational Linguistics 21. 203-225. https://doi.org/10.21236/ada324949.

Gundel, Jeanette K., Nancy Hedberg \& Ron Zacharski. 1993. Cognitive status and the form of referring expressions in discourse. Language 69. 274-307. https://doi.org/10.2307/416535.

Gürel, Ayse. 2003. Is the overt pronoun constraint universal? Evidence from L2 Turkish. Proceedings of the Generative Approaches to Second Language Acquisition Conference 6. $130-139$.

Gürel, Ayse. 2004. Selectivity in L2-induced L1 attrition: A psycholinguistic account. Journal of Neurolinguistics 17(1). 53-78.

Haegeman, Liliane. 1990. Understood subjects in English diaries. Multilingua 9(2). 157-199.

Haegeman, Liliane. 1997. Register variation, truncation, and subject omission in English and in French. English Language and Linguistics 1(2). 233-270.

Hobbs, Jerry R. 1979. Coherence and coreference. Cognitive Science, 3, 67-90.

Huang, C. T. James. 1984. On the distribution and reference of empty pronouns. Linguistic Inquiry, 531-574.

Kaiser, Elsi. M. 2003. The quest for a referent: A crosslinguistic look at reference resolution. Philadelphia: University of Pennsylvania dissertation.

Kaiser, Elsi \& John C. Trueswell. 2008. Interpreting pronouns and demonstratives in Finnish: Evidence for a form-specific approach to reference resolution. Language and Cognitive Processes 23. 709-748. https://doi.org/10.1080/01690960701771220.

Kaiser, Elsi. 2011. On the relation between coherence relations and anaphoric demonstratives in German. In I. Reich et al. (eds.), Proceedings of Sinn und Bedeutung. 337-351.

Kaiser, Elsi \& Emily Fedele. 2019. Reference resolution: A psycholinguistic perspective. In Jeanette Gundel \& Barbara Abbott (eds.), The Oxford handbook of reference. Oxford: Oxford University Press.

Kehler, Andrew. 2002. Coherence, reference, and the theory of grammar. Stanford: CSLI.

Kehler, Andrew, Laura Kertz, Hannah Rohde \& Jeffrey L. Elman. 2008. Coherence and coreference revisited. Journal of Semantics 25. 1-44. https://doi.org/10.1093/jos/ffm018.

Kehler, Andrew \& Hannah Rohde. 2013. A probabilistic reconciliation of coherence-driven and centering-driven theories of pronoun interpretation. Theoretical Linguistics 39(1-2). 1-37.

Kertz, Laura, Andrew Kehler \& Jeffrey Elman. 2006. Grammatical and coherence-based factors in pronoun interpretation. Proceedings of the Annual Conference of the Cognitive Science Society 28. 1605-1610. 
Kim, Kitaek, Theres Grüter \& Amy J. Schafer. 2013. Effects of event-structure and topic/focusmarking on pronoun reference in Korean. Poster presented at the 26th Annual CUNY Conference on Human Sentence Processing, Columbia, SC.

Kweon, Soo-Ok. 2011. Processing null and overt pronoun subject in ambiguous sentences in Korean. International Journal of Linguistics 3(1). 1-13.

Ngo, Binh. 2019. Vietnamese pronouns in discourse. Los Angeles: University of Southern California dissertation.

R Core Team. 2020. R: A language and environment for statistical computing. R Foundation for Statistical Computing, Vienna, Austria. URL http://www.R-project.org/

Roberts, Leah, Marianne Gullberg, \& Peter Indefrey. 2008. Online pronoun resolution in L2 discourse: L1 influence and general learner effects. Studies in Second Language Acquisition 30(3). 333-357. https://doi.org/10.1017/S0272263108080480.

Rohde, Hannah \& Andrew Kehler. 2008. The bidirectional influence between coherence establishment and pronoun interpretation. Poster presented at the 21st Annual CUNY Conference on Human Sentence Processing.

Sheldon, Amy. 1974. The role of parallel function in the acquisition of relative clauses in English. Journal of Verbal Learning and Verbal Behavior 13(3). 272-281.

Smyth, Ron. 1994. Grammatical determinants of ambiguous pronoun resolution. Journal of Psycholinguistic Research 23. 197-229. https://doi.org/10.1007/bf02139085.

Sohn, Ho Min. 2019. Korean (Vol. 4). London: Routledge.

Song, Jina \& Elsi Kaiser. 2020. Effects of discourse factors on the interpretation of Korean null pronouns in subject and object position. Proceedings of the Linguistic Society of America 5(1). 655-669. https://doi.org/10.3765/plsa.v5i1.4751.

Sorace, Antonella. 2011. Pinning down the concept of "interface" in bilingualism. Linguistic Approaches to Bilingualism 1(1). 1-33.

Sorace, Antonella, \& Francesca Filiaci. 2006. Anaphora resolution in near-native speakers of Italian. Second Language Research 22(3). 339-368. https://doi.org/10.1191/0267658306sr271oa.

Sorace, Antonella \& Ludovica Serratrice. 2009. Internal and external interfaces in bilingual language development: Beyond structural overlap. International Journal of Bilingualism 13(2). 195-210. https://doi.org/10.1177/1367006909339810.

Stevenson, Rosemary J., Alexander W. Nelson \& Keith Stenning. 1995. The role of parallelism in strategies of pronoun comprehension. Language and Speech 38. 393-418. https://doi.org/10.1177/002383099503800404.

Ueno, Mieko and Andrew Kehler. 2010. The interpretation of null and overt pronouns in Japanese: Grammatical and Pragmatic factors. Proceedings of the Annual Conference of the Cognitive Science Society 32. 2057-2062.

Ueno, Mieko \& Andrew Kehler. 2016. Grammatical and pragmatic factors in the interpretation of Japanese null and overt pronouns. Linguistics 54(6). 1165-1221. https://doi.org/10.1515/ling-2016-0027.

Wolf, Florian, Edward Gibson \& Timothy Desmet. 2004. Discourse coherence and pronoun resolution. Language and Cognitive Processes 19(6). 665-675. https://doi.org/10.1080/01690960444000034. 